\title{
Iconicidade e classes de palavras: os ideofones na língua changana
}

\author{
Iconicity and parts of speech : \\ Changana's ideophones
}

\section{Heronides Moura}

Universidade Federal de Santa Catarina - UFSC

\section{Ezra Alberto Chambal Nhampoca}

Universidade Federal de Santa Catarina - UFSC

\begin{abstract}
Resumo: $O$ presente artigo tem como objetivo investigar a classe de palavras e função dos ideofones do changana, uma língua do grupo bantu ${ }^{1}$, falada na África do Sul, em Moçambique, na Suazilândia e no Zimbabwe. Ideofones são palavras que descrevem eventos/ações/cenas com algum detalhe marcante. A análise é baseada na teoria da Gramática de Construções Radical (CROFT, 2000; 2001). A hipótese defendida neste artigo é a de que, na língua changana, os ideofones constituem uma classe de palavras específica desta língua, e sua principal função é predicadora, embora cumpra essa função de forma diferente dos verbos, que são os predicadores prototípicos. Os ideofones são predicadores marcados, tanto no sentido de marcação funcional, quanto no sentido de marcação tipológica.
\end{abstract}

Palavras-chave: Ideofones; Classe de Palavras; Gramática de Construções Radical.

Abstract: This paper intends to investigate the part of speech and function of ideophones in Changana, a Bantu language, spoken in South Africa, Mozambique, Swaziland and Zimbabwe. Ideophones are words that describe events/actions/scenes which present a noticeable aspect. The analysis is based on Radical Construction Grammar (CROFT, 2000; 2001). The hypothesis put forward in this paper is that ideophones constitute a particular part of speech of Changana, whose function is predicative, even if ideophones in Changana are not the prototypical predicates. The verbs are the prototypical predicates in Changana. Ideophones are marked predicates, both in the sense of functional markedness, and in the sense of typological markedness.

Keywords: Ideophones; Parts of Speech; Radical Construction Grammar.

\footnotetext{
${ }^{1}$ Mantivemos a grafia mais tradicional bantu, pois é a mais usada na literatura sobre o assunto.
} 



\section{Introdução}

O changana é uma língua bantu, falada em quatro países na África, incluindo Moçambique, país no qual foram coletados os dados desta pesquisa. Este artigo aborda os ideofones, um conjunto de palavras geralmente pouco conhecidas. Os ideofones foram definidos pela primeira vez por Doke $(1935)^{2}$, mas a definição dada por este autor era um tanto vaga, e um dos objetivos deste trabalho é, justamente, buscar uma definição mais precisa dessa classe de palavras.

O objetivo principal do trabalho é discutir a classe de palavras constituída pelos ideofones na língua changana, ou seja, analisar se os ideofones são ou não uma categoria gramatical independente nessa língua e, consequentemente, descrever a função que nela desempenham. A nossa hipótese é que os ideofones do changana constituem uma classe gramatical específica e que eles desempenham a função predicadora, assim como os verbos, embora de uma maneira diferente, como veremos. A fim de examinar a identidade categorial e função dos ideofones no changana, recorremos à teoria da Gramática de Construção Radical (CROFT, 2000; 2001).

Tentaremos mostrar, também, que os ideofones formam uma classe de palavras com base em uma motivação icônica. Os ideofones são uma classe marcada, em relação aos verbos, e essa iconicidade da marcação é tanto formal, quanto funcional.

Este trabalho foi motivado, inicialmente, pela dificuldade de se definir se os ideofones do changana constituem ou não uma classe gramatical específica. Este artigo é uma tentativa de responder a esta pergunta e está estruturado da seguinte forma. $\mathrm{Na}$ seção 2, é apresentado um quadro mais amplo sobre o funcionamento e definição dos ideofones. Na seção 3 , discute-se a classe de palavras a que pertencem os ideofones. Para isso, é apresentado o conceito de

\footnotetext{
2 Doke (1935) definiu ideofone como sendo a associação entre um determinado som, cor, estado, dor, intensidade, etc. e a consequente reação na mente do indivíduo.
}

classe gramatical à luz da Linguística Cognitiva, mais concretamente na teoria de Croft (2000; 2001). Finalmente, sustentamos que os ideofones do changana constituem uma classe gramatical específica. Defendemos que os ideofones são palavras marcadas, envolvendo tanto a marcação tipológica, quanto a marcação funcional.

\section{0 que são os ideofones?}

Nesta seção, vamos focar na caracterização e definição dos ideofones da língua changana. O changana (S53, na classificação de GUTHRIE, 1967) é uma língua bantu. De acordo com (SITOE, 1996), o changana pertence ao grupo Tswa-Ronga (S.50, na classificação de Guthrie, 1967). Em Moçambique, o changana é falado nas províncias de Maputo, Gaza, Inhambane e na zona meridional das províncias de Manica e Sofala. (SITOE; NGUNGA, 2000). Para este trabalho, tomamos como referência a variante xidzonga da língua changana, uma vez que os dados foram recolhidos num local em que esta variante prevalece.

Uma dificuldade básica na caracterização dos ideofones é que este tipo de palavras não existe nas línguas indo-europeias (MITI, 2006; LANGA, 2004). Linguistas têm sido desafiados a apresentar uma definição precisa dessa classe de palavras, relacionadas à descrição de eventos (FERREIRA, 2011). Como já vimos, foi Doke (1935) quem primeiramente apresentou uma tentativa de definição dos ideofones. Ngunga (2004, p. 195) afirma que "em estudos anteriores a 1968, Doke $(1931,1935)$ incluía esta categoria de palavras no grupo das onomatopeias". Portanto, apesar de Doke (1935) ter introduzido o termo ideofone anteriormente, só a partir de 1968 é que se começa a considerá-los como uma categoria gramatical distinta das outras. Ainda sobre esta classe gramatical, Langa (2004, p. 59) defende que Doke "nomeou-os de ideofones por se ter apercebido que a terminologia que considera cinco categorias lexicais principais a saber: " $\mathrm{N}(\mathrm{ome})$, $\mathrm{V}$ (erbo), ADJ(ectivo), ADV(érbio) e PREP(osição) não cobre a semântica que estas palavras transportam". 
Os ideofones são comumente definidos como uma representação viva de uma ideia num som (DOKE, 1935; NGUNGA, 2004). No entanto, esta definição não é muito precisa e não ajuda muito na especificação da função desse tipo de palavra. SITOE (1996) defende ainda que os ideofones se caracterizam pelo seu alto grau de especificidade. Já BECK (2005) defende que ideofones são expressões sinestésicas que se distinguem, como classe, por meio de suas propriedades sintáticas, morfológicas e fonológicas; da tendência de ter uma função emotiva e de estarem associados à fala e a registos dramáticos da fala.

Sitoe (2012) considera que os ideofones fazem parte de uma das principais classes de palavras no changana. Ribeiro (2010) também alerta para o perigo de confundir estes com as onomatopeias. $O$ autor afirma que os ideofones podem ser semelhantes às onomatopeias no impulso e na emoção, mas diferem das onomatopeias pelo papel que desempenham na linguagem e na gramática. $A$ onomatopeia limita-se a imitar sons, enquanto que 0 ideofone, para além da imitação de sons, pode ainda expressar ações, modos, qualidades, estados, fenômenos da natureza, quietude, silêncio, etc. (RIBEIRO, 2010). Ribeiro (2010, p.129) acrescenta que "é difícil sintetizar e classificar o sentido destas palavras, tão largo é o seu campo". Ribeiro chega a afirmar que toda noção verbal, na língua changana, pode ser também expressa por um ideofone. Por esta razão, Ribeiro (2010) considera que os ideofones constituem uma classe de palavras sem correspondente nas gramáticas europeias; estas palavras já foram, equivocadamente, classificadas de advérbios, interjeições, onomatopeias, substantivos onomatopaicos, raízes primitivas, etc. (TORREND, (s.d); JUNOD, (s.d) apud RIBEIRO, 2010, p 129).

As definições até aqui apresentadas foram e continuam sendo relevantes para o estudo dos ideofones. Contudo, pensamos que elas são muito gerais e não distinguem claramente os ideofones de outras classes de palavras, em especial os verbos e advérbios. Assim como os verbos e advérbios, os ideofones predicam sobre eventos. Argumentamos que a característica dos ideofones é que eles, ao contrário dos verbos, não caracterizam o evento com base em seus traços fundamentais, mas focam em elementos periféricos de uma cena verbal. $\mathrm{E}$, ao contrário dos advérbios, os ideofones não estão ancorados em um verbo, realizando eles mesmos a função predicadora.

Além disso, os ideofones constituem uma classe iconicamente marcada em relação aos verbos. Do ponto de vista da marcação funcional, os verbos funcionam como a forma não marcada, e os ideofones, como a forma marcada. Uma forma marcada, do ponto de vista funcional, é usada em contextos mais restritos, ao passo que a forma não marcada é usada em contextos mais amplos e não específicos (AIKHENVALD, 2016). Os ideofones, justamente, são usados, na língua changana, em situações bem específicas, quando se quer ressaltar algum detalhe não central do evento referido.

Para melhor situar o leitor, apresentamos os exemplos abaixo, com os ideofones -cambùcambù, gìdigìdì e-pshandlà, comparando-os com os verbos mais ou menos equivalentes na língua changana. Chamamos atenção para o fato de nas glosas, o material linguístico que se encontra entre parênteses dizer respeito a ambos, o ideofone e o verbo, enquanto 0 que se encontra entre parênteses angulados é referente apenas ao ideofone e é este material que fornece os insights para distinguir os ideofones dos verbos. Por exemplo, a informação de que o deslocamento é feito com movimentos bruscos e intensos está contida no significado do ideofone cambùcambù, mas não no significado do verbo cambula. 
Quadro 1

\begin{tabular}{|l|lr|}
\hline Ideofone & Verbo \\
\hline $\begin{array}{l}\text {-cambùcambù id. de } \\
\text { caminhar ou correr }\end{array}$ & -cambula & v.i. \\
nu/pelado, como veio ao & pelado, como veio ao \\
mundo (o indivíduo do & mundo (o indivíduo do \\
sexo masculino). [COM & sexo masculino). \\
MOVIMENTOS \\
BRUSCOS \\
INTENSOS]
\end{tabular}

\section{Ideofone}

(1a) Zavala ate cambùcambù ndleleni!

\begin{tabular}{|c|c|c|c|}
\hline Zavala & $\underline{\mathrm{a}-\mathrm{te}}$ & Cambùcambù & ndlele-ni! \\
\hline $\begin{array}{l}1^{3} . \\
\text { Zavala }\end{array}$ & $\mathrm{MS}^{4} 1 \mathrm{VDef}^{5}$. & $\begin{array}{l}I^{6}=\mathrm{de} \\
\text { caminhar/corre } \\
\mathrm{rnu}\end{array}$ & $\begin{array}{l}\text { 9.rua- } \\
\text { LOC }^{7}\end{array}$ \\
\hline
\end{tabular}

'O Zavala caminhou nu, com movimentos intensos e bruscos, na rua!'

Verbo

(1b) Zavala acambule ndleleni!

\begin{tabular}{|l|l|l|}
\hline Zavala & a-cambul-e & ndlele-ni! \\
\hline 1. Zavala & $\begin{array}{l}\text { MS1- } \\
5^{8} . \text { caminhar/correr } \\
\text { nu-Passado }\end{array}$ & $9^{9}$.rua- LOC. \\
\hline
\end{tabular}

'O Zavala caminhou nu na rua!'

Nos exemplos em (1a), temos um agente, a entidade que caminha, (Zavala), temos o verbo defectivo (-te), que também marca o tempo passado e que se torna (ate) ao agregar o morfema a-. 0

\footnotetext{
3 Todos os números representam a classe nominal a que o elemento pertence. No caso, a classe nominal é a 1.

${ }_{5}^{4} \mathrm{MS}=$ Marca de sujeito.

${ }^{5}$ VDef=Verbo defectivo.

$6 \mathrm{ID}=$ Ideofone.

7 LOC=Locativo.

${ }^{8}$ Classe 15 no changana.

${ }^{9}$ Classe 9 no changana.
}

morfema a- funciona como marca do sujeito Zavala (de $3^{\text {a }}$ pessoa). Portanto, na forma ate temos a indicação da marca do sujeito e o tempo passado. $O$ verbo defectivo, assim designado na terminologia bantu, é uma espécie de verbo dicendi que tem a mera função de situar no tempo e aspectualmente a ação/estado descrito pelo ideofone, agregando todos os morfemas que seriam aglutinados ao verbo se a predicação se desse por meio de um. Portanto, o verbo defectivo agrega todos os morfemas que indicam tempo, aspecto, número, pessoa.

No changana, esses morfemas se aglutinam ao verbo (esta é mais uma diferença entre verbos e ideofones). Uma vez que o ideofone não aglutina esses morfemas, eles se agregam ao verbo defectivo, como em "Zavala ate cambùcambù ndleleni!", em que - morfema que indica pessoa, número, a- está agregado ao verbo defectivo -te e não ao ideofone, contrariamente ao que ocorre em (1b), onde o morfema a- (marca de sujeito) e o morfema -e, marca de passado, aglutinam-se ao verbo -cambul-. O verbo defectivo, na sua estrutura semântica, só tem traços temporais e aspectuais. Não se consegue descrever nada com estes verbos; a função deles é a de introduzirem os ideofones e/ou os discursos direto e indireto.

O ideofone cambùcambù descrito acima significa caminhar/correr nu, mas não abrange alguém do sexo feminino, aplicando-se apenas ao homem. O verbo cambula também tem o significado de caminhar/correr nu, porém, o ideofone exprime isso de forma mais intensa e icônica e mais expressiva, daí que entendemos que a tradução não pode ser a mesma quando, por um lado se trata do ideofone e de outro lado, quando se trata de um verbo.

O nosso ponto, portanto, é que, formalmente, ideofones e verbos são classes distintas. Do ponto de vista semântico, ambas as classes servem para predicar sobre eventos, mas o fazem de maneira distinta: os verbos, correspondendo à forma funcionalmente não marcada, indicam eventos mais genéricos, ao passo que os ideofones, correspondendo à forma funcionalmente marcada, 
indicam eventos com algum detalhe bem específico (no caso, a brusquidão e intensidade do movimento).

A seguir, damos o exemplo do ideofone gìdìgìdi:

\section{Quadro 2}

\begin{tabular}{|c|c|}
\hline Ideofone & Verbo \\
\hline -gìdìgìdì id. de & -gìdìkà v.i. movimentar-se \\
\hline movimentar-se & em massa (diz-se \\
\hline $\begin{array}{l}\text { massa } \\
\text { IMPETUOSAMENTE] }\end{array}$ & $\begin{array}{l}\text { alguns animais e de } \\
\text { pessoas). }\end{array}$ \\
\hline $\begin{array}{l}\text { (diz-se de alguns } \\
\text { animais e de pessoas). }\end{array}$ & \\
\hline
\end{tabular}

\section{Ideofone}

(2a) Tihomu tite gìdìgìdì tiya combeni ${ }^{10}$.

\begin{tabular}{|c|c|c|c|c|}
\hline Tihomu & $\underline{\text { ti-te }}$ & gìdìgìdì & tiya & $\begin{array}{l}\text { comb } \\
\text { e-ni }\end{array}$ \\
\hline $\begin{array}{l}\text { MS10 } \\
\text { bois }\end{array}$ & $\begin{array}{l}\text { MS10- } \\
\text { Vdef. }\end{array}$ & $\begin{array}{l}\mathrm{ID}=\mathrm{de} \\
\text { movimen } \\
\text { tar-se } \\
\text { em }\end{array}$ & MS10.15.ir & $\begin{array}{l}\text { 5.rio- } \\
\text { LOC }\end{array}$ \\
\hline
\end{tabular}

'Os bois movimentaram-se em massa e (impetuosamente) para o rio'.

\section{Verbo}

(2b) Tihomu tigidike tiya combeni.

\footnotetext{
${ }^{10}$ Sobre o plural "bois", observamos que no changana a maior parte das classes nominais funciona aos pares e no par 9-10, 9 é o singular e o 10 plural. As classes são:

$1-2$

$3-4$

$5-6$

7-8

$9-10$

11-10 (onze faz plural com 10, também)

14 (não tem plural, é a classe dos nomes abstratos)

15 não tem plural (classe dos verbos)

16,17 e 18 (são as classes locativas)

21 (sem plural, classe dos aumentativos pejorativos).
}

'Os bois movimentaram-se em massa para o rio'.

\begin{tabular}{|l|l|l|l|}
\hline Tihomu & ti-gidike & ti-ya & combe-ni \\
\hline MS10 bois & $\begin{array}{l}\text { MS10-15. } \\
\text { movimenta } \\
\text { r-se em } \\
\text { massa }\end{array}$ & $\begin{array}{l}\text { ir 10-15. } \\
\text { 5.rio-LOC }\end{array}$ & \\
\hline
\end{tabular}

Em (2a), temos o verbo defectivo (-te) que se torna (tite) ao agregar o morfema ti- que funciona como marca, de $3^{\text {a }}$ pessoa, do sujeito tihomu ('bois'). No exemplo em (2b), temos um agente, que é a entidade que se movimenta em massa (tihomu 'bois') e o verbo gìdikà, que, ao se combinar com o morfema ti- (marca de $3^{\mathrm{a}}$ pessoa), dá a forma tigidike.

Assim, do ponto de vista semântico, se comparamos os exemplos $2 \mathrm{a}$ e $2 \mathrm{~b}$, vemos que $\mathrm{a}$ situação indicada pelo verbo é mais normal e corriqueira, ao passo que a situação indicada pelo ideofone apresenta uma característica mais específica e mais notável, correspondendo, assim, à forma marcada, do ponto de vista funcional.

$\mathrm{Na}$ sequência, apresentamos o ideofone pshandlà:

Quadro 3.

\begin{tabular}{|c|c|}
\hline Ideofone & Verbo \\
\hline $\begin{array}{l}\text {-pshandlà id. 1. de cair e } \\
\text { se esborrachar, rebentar- } \\
\text { se [COMPLETAMENTE] } \\
\text { (p. e., frutos maduros e } \\
\text { coisas empapadas, } \\
\text { geralmenter em } \\
\text { superfícies sólidas); 2. de } \\
\text { (fazer) rebentar } \\
\text { [COMPLETAMENTE] } \\
\text { (por exemplo, frutos } \\
\text { maduros e coisas } \\
\text { empapadas, geralmente } \\
\text { em superfícies sólidas). }\end{array}$ & $\begin{array}{l}\text {-pshandaka/- } \\
\text { pshandlasa v.i.\&t. 1. de } \\
\text { esborrachar-se, } \\
\text { rebentar-se (p. e., frutos } \\
\text { maduros e coisas } \\
\text { empapadas, geralmente } \\
\text { em superfícies sólidas); } \\
\text { 2. de (fazer) rebentar (por } \\
\text { exemplo, frutos maduros } \\
\text { e coisas empapadas, } \\
\text { geralmente } \\
\text { superfícies sólidas). }\end{array}$ \\
\hline
\end{tabular}

\section{Ideofone}

(3a) Payipayi rite pshandlà!

\footnotetext{
${ }^{11}$ Classe 10 no changana.
} 


\begin{tabular}{|l|l|l|}
\hline Payipayi & ri-te & pshandlà! \\
\hline $5^{12}$. Mamão & $\begin{array}{l}\text { MS5- } \\
\text { VDef. }\end{array}$ & $\begin{array}{l}\text { ID = de cair e se } \\
\text { esborrachar } \\
\text { completamente }\end{array}$ \\
\hline
\end{tabular}

"O mamão (maduro) caiu e se esborrachou completamente!"

\section{Verbo}

(3b) Payipayi ripshandlàkile!

\begin{tabular}{|l|c|}
\hline Payipayi & Ri-pshandlàk-ile \\
\hline 5. mamão & $\begin{array}{c}\text { MS5- 15. cair e se } \\
\text { esborrachar- Passado }\end{array}$ \\
\hline
\end{tabular}

"O mamão (maduro) caiu e se esborrachou!"

O ideofone pshandlà indica tanto a intensidade da ação, quanto a sua completude (o mamão se esborrachou totalmente no chão), porém, não se trata de um advérbio de modo, pois o próprio ideofone cumpre a função predicadora e a modificadora, ao mesmo tempo. Ou seja, o ideofone marca um evento com características mais típicas, mas cumpre a mesma função predicadora de um verbo.

Note-se que, nas sentenças com ideofones, não é necessária a ocorrência dos verbos que exprimem ações que tradicionalmente são descritas por verbos. Os ideofones, por si só, desempenham a função predicadora e tornam as sentenças com ideofones sinônimas das que ocorrem com verbos, em termos de condições de verdade. Ou seja, os exemplos 3a e 3b indicam, ambos, uma situação em que o mamão se esborrachou no chão, mas o ideofone marca que o evento em $3 a$ foi muito mais

\footnotetext{
${ }^{12}$ Classe 5 no changana.
}

intenso e completo: 3a indica um subconjunto mais específico da situação mais geral descrita em 3b.

\section{A abordagem da Linguística Cognitiva na definição de classe de palavras: o modelo da Gramática de Construções Radical}

De acordo com Silva e Batoréo (2010), a distinção mais essencial que a maioria das línguas codifica é a que opõe nomes e verbos. Os autores pontuam que isto reflete uma divisão conceptual do mundo que os falantes fazem, a qual consiste na distinção entre entidades e relações. Para Silva e Batoréo (2010, p. 235), "nomes perfilam 'coisas' ou regiões num determinado domínio e as restantes categorias gramaticais perfilam 'relações ou interconexões entre coisas". Este posicionamento explica por que motivo os nomes são tidos como a categoria básica nas línguas (AITCHISON, 1996).

Aitchison (1996) atesta que os nomes nas línguas do mundo gozam de primazia e a 'nomenclatura' é a principal evidência disso. Esse autor afirma que a primazia dos nomes nas línguas, provavelmente, terá causado a explosão na nomeação das coisas (naming insight) e, os nomes das coisas devem ter produzido outro tipo de palavras logo no início da evolução da linguagem, sobretudo verbos. O estatuto básico dos nomes é suportado por outras evidências, como, por exemplo, no fato de, na maioria das línguas, normalmente ser mais fácil transformar um substantivo em um verbo e não o contrário

Aitchison (1996) argumenta também que a maior parte das línguas do mundo possui mais nomes que verbos. Em inglês, por exemplo, o número de nomes é aproximadamente três vezes maior que o dos verbos. Este fato explica o fato de os verbos serem mais polissêmicos que os nomes. Em geral, os verbos apresentam aproximadamente três significados, enquanto que a maioria dos nomes possui até cerca de dois significados apenas (AITCHISON, 1996).

Nomes e verbos provavelmente constituam a primeira gramática, ou seja, o mínimo essencial para 
a gramática de uma língua. Existem diferentes modelos cognitivos de gramática (SILVA; BATORÉO, 2010). Os autores destacam três: a Gramática Cognitiva de Langacker (1987, 2008); a Gramática de Construções inspirada em trabalhos de Fillmore (1988) e desenvolvida por Goldberg (1995) e a Gramática de Construções Radical de Croft (2000, 2001).

$\mathrm{Na}$ visão cognitiva da gramática, esta é um sistema de estruturação conceptual, envolvendo não só capacidades linguísticas, mas também as capacidades cognitivas, tais como a percepção, a atenção, a categorização, a memória, o conhecimento do mundo, remetendo, deste modo uma semântica enciclopédica (SILVA; BATORÉO, 2010, p. 230). Neste artigo, vamos focar na Gramática de Construção Radical (CROFT, 2000; 2001), pois esta oferece um instrumental interessante para a descrição de classes gramaticais identificáveis em línguas específicas, como é o caso dos ideofones, na língua changana.

De acordo com Croft (2001), a Gramática de Construções Radical fundamenta-se nos seguintes princípios: 1) as classes gramaticais não devem ser consideradas como primitivos, mas sim como construções específicas nas línguas; 2) as construções são as unidades primitivas de representação sintática; 3) não existem relações sintáticas independentes da construção e 4) as construções são específicas de cada língua e não universais. Com base nestes princípios, pode-se fazer a descrição de classes gramaticais internamente a uma dada língua. É o que propomos para a categoria gramatical e também para a função dos ideofones do changana.

Croft (2000) faz uma breve análise da classificação tradicional de classes de palavras, baseada em uma definição nocional, segundo a qual substantivos denotam pessoas, lugares ou coisas; adjetivos denotam propriedades/qualidades e verbos denotam ações/eventos. Croft (2000) reafirma que esta definição baseada na classe semântica dos itens lexicais é insuficiente e inadequada, pois na verdade, palavras de uma classe semântica qualquer podem ocorrer ou funcionar como de outra(s) classes. Vejamos um exemplo do adjetivo certo:

(4) a) O certo é escolher um dia próximo para a defesa.

b) Ele escolheu o dia certo para a defesa.

c) Ele falou certo na hora certa.

Como se pode verificar, apesar de haver consenso de que certo é um adjetivo, apenas na frase (4b) é que esta palavra desempenha, de fato, essa função. Em (4a) ocorre como nome, e em (4c) como advérbio. Por esta razão, como pontua Croft (2000), a análise nocional tem sido rejeitada, pois não dá conta do caráter dinâmico e multifuncional das palavras das línguas.

Croft (2001, p. 64) afirma que a maioria das teorias sintáticas recorre a duas características binárias, $[ \pm N]$ e $[ \pm V]$, para definir nomes, verbos, adjetivos e preposição. Este tipo de análise se destina a captar elementos de semelhança e de diferença no comportamento sintático destas partes do discurso. Contudo, os proponentes desse tipo de análise não deixam claro em que teoria se baseiam para definir as quatros categorias como tal.

No caso específico da teoria gerativa, a maioria dos esforços, segundo Croft (2001, p. 64) tem sido no sentido de identificar padrões sintáticos das principais classes de palavras e, mais recentemente, de partes menores também, como afixos flexionais, por exemplo. No entanto, não são fornecidos critérios que permitam distinguir as classes de palavras em uma língua particular, pois se assume que as características binárias $[ \pm \mathrm{N}]$ e $[ \pm \mathrm{V}]$ são intrínsecas a todas as línguas. Essa metodologia termina não oferecendo uma heurística satisfatória para a descrição das classes de palavras existentes nas línguas específicas.

Essa falta de critérios para identificação das classes de palavras é um problema comum na descrição sintática. Como diz Langacker (1987, p. 2), "Todo linguista se apoia nestes conceitos, mas poucos linguistas ou talvez nenhum esteja preparado 
para defini-los de forma adequada, explícita e esclarecedora". ${ }^{13}$

Croft (2001) coloca a questão da seguinte forma: como sabemos que uma dada categoria gramatical numa língua exótica $x$ corresponde efetivamente à categoria nome, verbo, etc., nas línguas europeias? Consideramos esta questão fundamental para o tratamento dos ideofones do changana, pois apesar de não considerarmos 0 changana uma língua exótica, ela é uma língua pouco conhecida universalmente. Sendo assim, o que se verifica, frequentemente, é uma tentativa de encaixar os ideofones em classes (tais como verbos ou advérbios) já definidas na maioria das línguas mais estudadas.

Croft (2000, p. 83) afirma que para uma definição adequada das classes de palavras ${ }^{14}$ é preciso: 1) Estabelecer critérios claros para a distinção de classes e subclasses de palavras; 2) Encontrar critérios interlinguísticos para definir classes universais e 3) Reconhecer que as fronteiras entre as classes de palavras são próprias de cada língua.

Croft (2000) funde as noções funcionais e formais das classes de palavras, ao recorrer à noção de universais tipológicos, baseados no conceito de marcação tipológica. Para o autor, a marcação tipológica difere do princípio de marcação desenvolvido na Escola de Praga (CROFT, 2001, p. 89). A diferença é que a marcação tipológica é uma propriedade universal de uma categoria conceitual e não uma categoria gramatical específica de uma língua particular, como ocorre na teoria da marcação desenvolvida pela escola de Praga. $O$ autor exemplifica: "quando se afirma que o singular é tipicamente não marcado, uma hipótese está sendo apresentada sobre a forma como a categoria conceitual singular está codificada nas línguas do mundo, e não a categoria gramatical singular

\footnotetext{
${ }^{13}$ Tradução dos autores. O original é "Every linguist relies on these concepts but few if any are prepared to define them in an adequate, explicit and revealing way" (LANGACKER ,1987, p. 2).

Em língua inglesa, utiliza-se comumente o termo "parts of speech" (partes da fala) para designar as classes de palavras, que é o termo que estamos usando neste trabalho.
}

encontrada em inglês ou qualquer outra língua particular" (CROFT, 2000, p. 88). Portanto, categorias conceptuais são universais e não marcadas, enquanto categorias gramaticais são definidas pelas línguas particulares.

Nessa linha de pensamento, Croft (2001) argumenta que nas línguas há correlações não marcadas de função pragmática e de classe semântico-lexical (Nome - refere-se a objetos; Adjetivo - modificação de propriedades e Verbo predicação de ações), no entanto, qualquer outra combinação de função pragmática e classe semântico-lexical que não seja a explicada anteriormente, é marcada. Essas combinações não marcadas são categorias conceituais. $O$ fato de que as combinações acima são não marcadas e as outras possíveis combinações são marcadas conduz-nos a uma hipótese sobre um padrão de variação dessas categorias conceituais e como são codificadas em línguas particulares.

As especificidades das construções nesta teoria abrangem construções que têm as seguintes funções nas línguas: predicação, referência e modificação. Estas três funções pragmáticas são, de fato, a base para a distinção das três tradicionais e principais categorias de palavras: Nome, Verbo e Adjetivo. Para Croft (2001), esta constatação seria o primeiro passo para a identificação das 'grandes' partes do discurso em oposição com as 'menores'.

Nesta abordagem, reconhece-se a existência de universais semânticos e não formais, mas também se tem em conta que há fatores linguísticos particulares das línguas. Assim, Croft (2001) põe em causa a questão dos universais linguísticos absolutos e afirma que as classes gramaticais são construções específicas das línguas. Por exemplo, ele considera que as categorias substantivo, verbo e adjetivo, consideradas tradicionalmente como universais linguísticos, são universais tipológicos, isto é, estas categorias apresentam apenas padrões sistemáticos de variação nas línguas do mundo, uma vez que, na teoria tipológica, não se pode prever 0 seu comportamento exato em línguas individuais e em vez de "forçar" o encaixe uniforme em todas as 
línguas do mundo, prevê-se que cada língua se encaixe em algum lugar da variação do padrão permitido pela teoria da marcação tipológica.

Com isso, Croft (2001) conclui que categorias gramaticais são de línguas específicas, sendo definidas pelas construções dessas línguas. Universais linguísticos não são um modelo de estrutura gramatical, mas sim padrões sistemáticos de variação. Croft (2001) argumenta que as partes do discurso devem ser identificadas como protótipos funcionais, ou seja, deve-se identificar qual é a função de uma dada palavra ou conjunto de palavras na língua.

Os termos substantivo, verbo e adjetivo não descrevem categorias gramaticais de uma língua particular, mas sim, protótipos funcionais. Um protótipo descreve o núcleo de uma categoria e não o limite dessa categoria. A estrutura prototípica de uma categoria é fornecida por uma teoria universal, enquanto que seus limites são fornecidos pela gramática particular da língua.

Com base nesta teoria, verificamos que os ideofones do changana se encaixam num padrão de variação correspondente à predicação. Os ideofones correspondem a um predicador marcado, ou seja, a categoria conceitual predicação, nessa língua, é realizada por duas classes semânticas, a saber: i) elementos não marcados, que são os verbos e ii) os elementos marcados, que são os ideofones. Os ideofones correspondem a uma variação tipológica dos predicadores, não correspondendo à predicação prototípica.

No changana, os verbos são os predicadores prototípicos, o que está de acordo com o princípio da marcação tipológica: "nomes, adjetivos e verbos são emparelhamentos prototípicos de respectivamente, referência/objeto, modificação/propriedade e predicação/ação" (SILVA; BATORÉO, 2010, p. 236). $\mathrm{O}$ ideofone se enquadra no espaço bidimensional que combina a classe semântica ações e a função discursiva de predicador. Em suma, nossa hipótese é que, na língua changana, os verbos são os predicadores prototípicos e os ideofones, predicadores marcados.
Os ideofones na língua changana, apesar de serem marcados, tanto morfologicamente, quanto funcionalmente (pois se referem a eventos muito específicos), atuam como predicadores, sem a necessidade de qualquer ancoragem em um verbo. Retomamos, para exemplificação, a frase (3a):
3a) Payipayi ri-te
pshandlà
5. mamão
MS5-VDef.
ID = de cair e se
esborrachar
'O mamão (maduro) caiu e se esborrachou completamente!'

O ideofone, em (3a), funciona como predicador, embora de uma forma marcada (ocorre com um verbo defectivo que situa o ideofone temporal e aspectualmente). Obedece-se, assim, ao princípio de codificação estrutural (CROFT, 2001, p. 90):

Codificação estrutural: Se uma língua codifica um membro tipologicamente não marcado de uma categoria gramatical por meio de $n$ morfemas $(n \geq 0)$, então ela codifica um membro tipologicamente marcado daquela categoria por meio de ao menos $\mathrm{n}$ morfemas.

Ou seja, o acréscimo obrigatório do verbo defectivo ao ideofone indica que ele é um membro marcado da categoria de predicadores do changana.

Verifica-se também que, na frase (3a), não é necessária a ocorrência dos verbos que exprimem a ação de esborrachar(se). O ideofone, por si só, desempenha a função predicadora. A única diferença em relação ao verbo, de natureza pragmática e conceitual, é que o ideofone explicita uma situação atípica, em que se ressalta algum aspecto não central da cena verbal. No caso, o aspecto não central da cena é a forma extrema e completa da ação verbal referida. Ou seja, as frases que ocorrem com ideofones são sinônimas das que ocorrem com verbos (aceitando que sinônimos são itens lexicais cujos sentidos são semelhantes no que diz respeito aos traços semânticos "centrais", ou seja, traços dados pelo predicador básico - não marcado (verbo), mas que podem diferir nos seus traços "periféricos", ou seja, traços dados pelo predicador não básico, ou seja, os ideofones).

Para os falantes do changana, haverá uma diferença de interpretação, pois os ideofones 
(predicadores não prototípicos) acrescentam nuances "periféricas" ao sentido "central" dos verbos (predicadores prototípicos). As nuances periféricas aqui referidas resumem-se ao fato de o ideofone destacar um elemento não central de um frame, com destaque para algum elemento da cena, que o verbo não destacaria. O ideofone acrescenta, ao sentido básico dado pelo verbo, nuances que envolvem intensidade e expressividade, as quais são agregadas ao significado proposicional (dado pelo verbo).

\section{Conclusão}

Como visto, os ideofones do changana desempenham a função predicadora: predicam ações de entidades. Os ideofones constituem uma classe de palavras particular da língua changana. De fato, na perspectiva da Gramática de Construções Radical, toda categoria gramatical é irredutivelmente particular a uma língua, pois toda categoria gramatical deriva de construções, que se caracterizam pelo particularismo (CROFT, 2001, p. 86).

Se se assume uma segmentação extremada dos particularismos linguísticos, a consequência é que não seria possível construir qualquer tipologia linguística e que, em especial, não faria sentido falar em classes de palavras de caráter universal, pois "as línguas podem diferir entre si de maneira ilimitada e imprevisível”" No entanto, a Gramática das Construções Radical (apesar do radical do nome) se opõe a esse relativismo linguístico extremo, característico do estruturalismo americano (MOURA; CAMBRUSSI, no prelo). A Gramática das Construções Radical assume universais linguísticos de natureza implicacional, tais como: eventos tendem a ser representados pela classe semântico-lexical dos verbos, que são as formas não marcadas da função predicativa. Logo, o vínculo entre classes de palavras universais (como os verbos) se dá entre as construções (específicas de uma língua) e as funções

\footnotetext{
15 Tradução dos autores. O original é: "languages could differ from each other without limit and in unpredicatable ways" (JOOS, 1957, p. 96).
}

(como a predicação), que são universais. Assim, diferentes construções (nas diferentes línguas) se organizam em torno das funções de atos proposicionais (predicação, referência e modificação), que são universais (CROFT, 2001, p. 87). Caracteristicamente, essas funções são representadas por verbos, nomes e adjetivos, respectivamente.

No changana, os verbos são a classe de palavras prototipicamente associada à função predicativa, em conformidade com a teoria dos universais descrita acima. No entanto, além dos verbos, há outra classe de predicadores, no changana. Essa classe é a dos ideofones.

A teoria da Gramática das Construções Radical prevê que sempre que uma classe distinta dos verbos assume a função predicativa, então essa classe será marcada, em relação aos verbos. Esse é o princípio da marcação tipológica. $E$ é isso que de fato acontece, no changana.

Além disso, essa marcação é também funcional, pois os eventos predicados pelos ideofones são muito mais específicos que os eventos indicados pelos verbos com os quais os ideofones contrastam.

Assim, não parece haver uma contradição entre marcação tipológica e marcação funcional, no caso dos ideofones, ao contrário da oposição feita por Croft (2001, p. 89) entre os dois tipos de marcação. De fato, a marcação funcional parece ser a motivação icônica por trás da constituição da classe dos ideofones.

A função predicadora, no changana, é prototipicamente desempenhada pelos verbos e os ideofones seriam predicadores não prototípicos, usados geralmente para situações específicas de comunicação. Por essa razão, na literatura tradicional sobre o tema, atribui-se aos ideofones a característica de serem expressões sinestésicas que apresentam uma tendência de ter uma função emotiva/expressiva e de estarem associados à fala e a registos dramáticos da fala, assim como uma representação viva de uma ideia, num som (KIMENYI, [s.d]).

Estamos cientes de que nessa língua os verbos é que são predicadores prototípicos, mas 
como defende Ferrari (2014, p. 70), "todos os membros de uma classe compartilham propriedades semânticas fundamentais, e seus polos semânticos instanciam um esquema abstrato único". Nesse caso, verbos e ideofones compartilham um esquema abstrato único, mas, por outro lado, contrastam pela especificidade expressiva dos ideofones.

\section{Referências}

AICTHISON, J. The seeds of speech: language origin and evolution. Londres: Cambridge University Press, 1996.

AIKHENVALD, A. How gender shapes the world. Oxford: Oxford University Press, 2016.

BECK, D. Ideophones, adverbs and predicate modifiers in Upper Necaxa Totonac. Departament of Linguistics, University of Alberta, 2005.

CROFT, W. Parts of speech as language universals and as language-particular categories. In: COMRIE, B. Approaches to the typology of world classes. Berlim: Gruyter Mouton, 2000, p. 65-102.

CROFT, W. Radical Construction Grammar: syntactic theory in typological perspective. Oxford: Oxford University Press, 2001.

DOKE, C. Bantu Linguistic Terminology. London: Longman, 1935.

FERRARI, L. Introdução à Linguística Cognitiva. São Paulo: Contexto, 2014.

FERREIRA, M. Como são apresentados sons e imagens em Parkatêjê. Signótica, Goiânia, vol. 23, n. 2, p. 403-414, jul./dez. 2011.

FILLMORE, C. The mechanisms of 'Construction Grammar'. Berkeley Linguistics Society, 14, 1988, pp. 35-55.

GOLDBERG, A. Constructions: a construction grammar approach to argument structure. Chicago: The University of Chicago Press, 1995.

GUTHRIE, M. Comparative Bantu: an introduction to the Comparative linguistics and prehistory of the Bantu languages. Vol. 1. Letchworth: Gregg International, 1967.
KIMENY, A. Inconicity of ideophones in Kinyarwanda: form, function, content and context. Califórnia State University at Sacramento, Califórnia, [s.d]. Disponível em: http://www.kimenyi.com/iconicityof-ideophones-inkinyarwanda.php. Acesso em 26 de Maio de 2015.

JOOS, M. Readings in Linguistics I. Chicago: Chicago University Press, 1957.

LANGA, D. Ideofones em Changana. In: NGUNGA, A. \& PEREIRA, I. (orgs.). Progressos da Investigação em Ciências Sociais e Humanas. Maputo: Imprensa Universitária - Universidade Eduardo Mondlane, 2004. p. 59-77.

LANGACKER, R. Foundations of Cognitive Grammar. Vol. 1: Theoretical Prerequisites. Stanford: Stanford University Press, 1987.

Cognitive Grammar: a basic introduction. New York: Oxford University Press, 2008.

MITI, L. Comparative bantu phonology and morphology. Cape Town: CASAS, 2006.

MOURA, H.; CAMBRUSSI, M. Uma breve história da linguística. Petrópolis: Vozes, no prelo.

NGUNGA, A. Introdução à linguística bantu. Maputo: Imprensa Universitária - Universidade Eduardo Mondlane, 2004.

RIBEIRO, A. Dicionário Gramatical Changana. Maputo: Paulinas, 2010.

SILVA, A.; BATORÉ, H. Gramática Cognitiva: estruturação conceptual, arquitetura e aplicações. In: BRITO, A. (org.). Gramática: história, teorias, aplicações. Porto: Universidade do Porto, 2010, p. $229-251$

SITOE, B. Dicionário Changana - Português. Maputo: Instituto Nacional do Desenvolvimento da Educação (INDE), 1996.

Dicionário Changana - Português. $2^{\mathrm{a}}$ ed. Maputo: Textos Editores, 2012.

SITOE, B.; NGUNGA, A. Padronização da Ortografia de Línguas Moçambicanas: Relatório do II Seminário. Maputo: NELIMO, 2000.

\section{COMO CITAR ESSE ARTIGO}

MOURA, Heronides. Um caso de iconicidade em classes de palavras: os ideofones na língua changana. Signo, Santa Cruz do Sul, v. 42, n. 75, dez. 2017. ISSN 1982-2014. Disponível em: <https://online.unisc.br/seer/index.php/signo/article/view/11146>. Acesso em: doi: http://dx.doi.org/10.17058/signo.v42i75.11146. 